\title{
IMPLEMENTING COMPETENCY-BASED ASSESSMENT IN A FIRST YEAR ENGINEERING DESIGN COURSE
}

\author{
Brian Frank, Simon Bailey, Aphra Rogers \\ Queen's University \\ Brian.frank@queensu.ca, simon.bailey@queensu.ca, Aphra.rogers@queensu.ca
}

\begin{abstract}
Competency-based assessment (CBA) is increasingly of interest in higher education, particularly in the professions. This assessment approach requires that students demonstrate satisfactory performance in specified measurable outcomes for progression, rather than meeting a particular overall average in a range of assessments.
\end{abstract}

The paper describes the implementation of CBA in a first year engineering design and practice course. Each competency was linked to multiple assessment points to allow multiple opportunities to meet the competency without requiring the teaching staff to regrade assignments that did not meet expectations. The structure was designed to use no new additional course personnel. Based on this work the team recommends using past grades and learning outcome data the likely consequences of applying CBA to course assessment schemes, running CBA in parallel with a traditional grading scheme, and planning for flexibility in the grading scheme. Applying CBA to authentic activities was much more complex than for individual tests.

Keywords: competency-based assessment, first year engineering, engineering design and practice

\section{INTRODUCTION}

Competency-based assessment (CBA) is increasingly of interest in higher education, particularly in the professions. This assessment approach requires that students demonstrate satisfactory performance in specified measurable outcomes for progression, rather than meeting a particular overall average in a range of assessments as is commonly used. It is a core element in some medical education programs [8] and is being explored in engineering programs including in Canada $[2,3,5,6]$.

Competency-based assessment is being used by the Canadian Engineering Qualifications Board (CEQB) and provincial regulators to evaluate candidates for licensure who were educated outside Canada [9]. It supports constructive alignment and clearly communicates to students the importance of meeting key requirements during an educational experience $[1,4]$.

CEEA-ACEG21; Paper 117

University of Prince Edward Island; June $21-23,2021-1$ of 5 -
In engineering educational literature there are a large number of competency-based examples to draw upon, for a range of purposes including increasing student diversity, providing flexibility for "non-traditional" students (i.e., not direct from secondary education), and supporting improved learning [4]. Competency-based education can involve a range of significant deviations from the commonplace approach to engineering education in Canada; for the purposes of this paper, the context is a project-based design course where students are required to demonstrate learning on defined competencies. Since students were also required to achieve a passing grade in the course $(50 \%$ using a weighted average of course deliverables), it allows comparison of student abilities with and without using a CBA approach.

\section{IMPLEMENTATION}

A first-year engineering design and practice course at a medium-sized Canadian engineering program has been assessing the majority of the CEAB graduate attributes for almost ten years. Data arising from that process have shown consistently that though the majority of students meet expectations, a minority fall below expectations in elements like written communications, ability to develop and use a mathematical model of a system, and ability to meaningfully reflect and plan for improvement.

In an attempt to use this information to improve student performance more quickly, in the fall of 2019 the course piloted a form of CBA in parallel with the standard course grading scheme to evaluate the administrative complexity of CBA in the course environment and impact on student performance. The course had approximately 800 students taught using a blended format involving weekly readings and individual quizzes, a weekly classroom active learning session, and team-based project activities, similar to past years. The number of assessment points stayed relatively constant compared to previous years; this is an important consideration since CBA implementations may involve regrading any student work which does not meet the 
required level of performance. That approach was not used in this pilot.

Students were informed that there were two requirements to pass the course: (1) Students received final grades calculated as a weighted average of individual deliverables, as is common practice in Canadian engineering programs, and (2) Students were required to a demonstrate a threshold level of performance in four competencies that are important for future courses and often not demonstrated by students. These competencies are:

- Create and use quantitative models to analyze systems ("Modelling")

- Effectively communicate in written form following disciplinary conventions and using standard grammar and mechanics ("Communication")

- Work effectively and respectfully in a team ("Teaming")

- Critically reflect on self and team performance ("Reflection")

Each of those were aligned with and assessed on activities throughout the term. Modeling, Communication and Reflection were assessed using a rubric dimension embedded into specific deliverables. Teaming was assessed by the instructional team based on observations, stated workload distribution on team reports, and peer evaluation using the ITPMetrics platform [7]. Each competency needed to be demonstrated in both supervised and non-supervised settings to compare performance in authentic but non-supervised settings (e.g., in an individual assignment submitted to the LMS) and vs. more restrictive but supervised settings (e.g., on a written test).

Students had to pass both supervised and non-supervised assessments at a grade of $60 \%$ or higher for each competency. Figure 1 shows a summary of the assessment points aligned with the competencies over the duration of the 12 blocks in the term, where a block roughly corresponds to 7 days. Students were required to meet the minimum level of competency at least once in the course, aside from Teaming where the final evaluation was based on performance throughout the term. The multiple assessment points were intended to allow multiple opportunities to meet the competency without requiring the teaching staff to regrade assignments that did not meet expectations, similar in principle to the "chain" of assessments used for this purpose at the University of Saskatchewan [2]. The structure was designed to use no new additional course personnel.

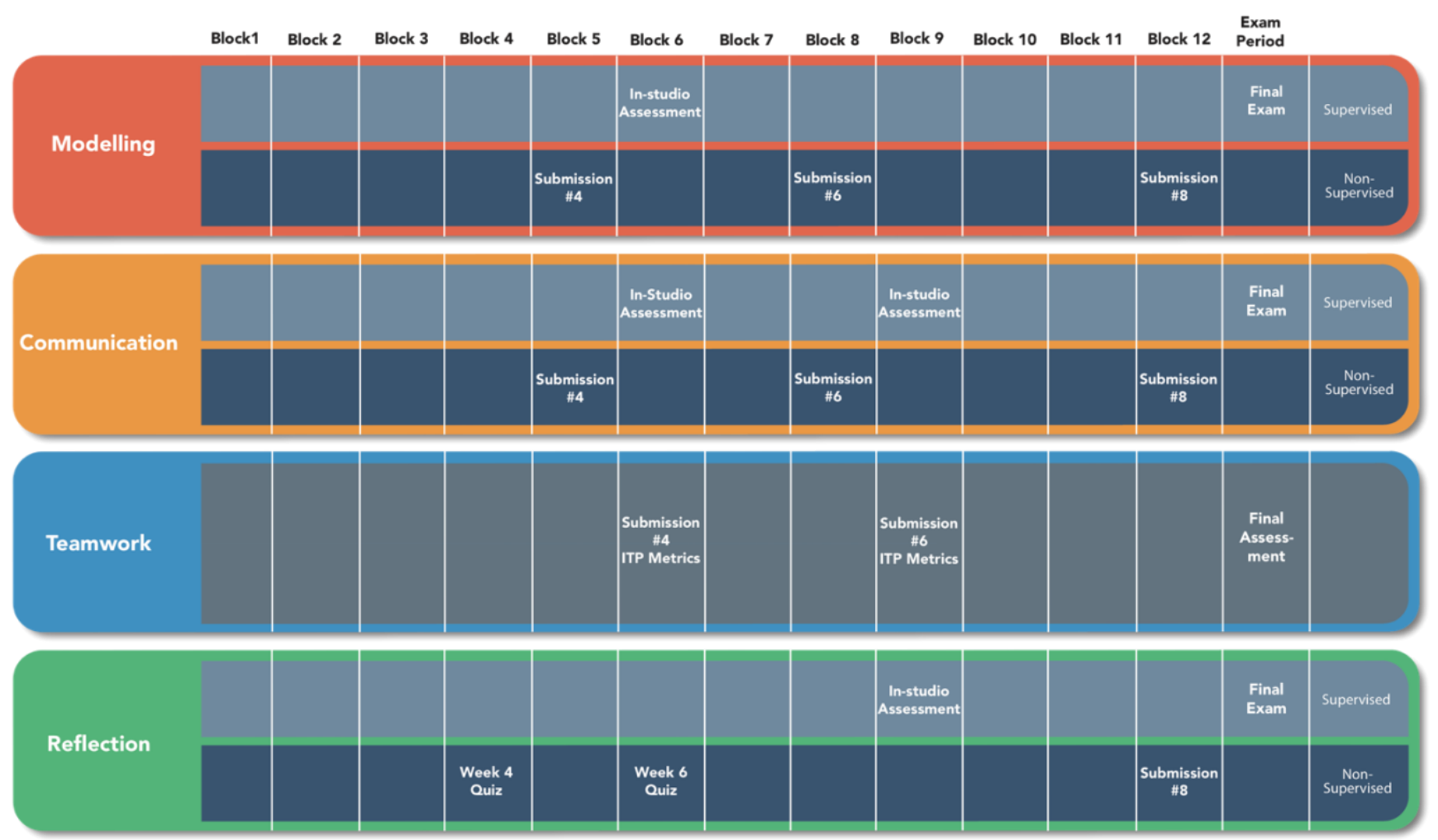

Figure 1 - Original alignment of competencies to assignments (not including changes made during the course) 
The key course assessments linked to the competencies are as follows:

- Submission 4: Project Subsystem Mathematical Model (individual report)

- Submission 5: Project Analysis of Stakeholders, Equity, and Environmental impact (team)

- Submission 6: Project Implementation Report (team and individual)

- Submission 7: Professionalism and Ethics Scenarios (team)

- Submission 8: Project Design Final Report (team)

- In-studio Assessments: Scenarios to evaluate modeling and written communications

- Peer evaluations using ITP Metrics were used throughout course to evaluate teaming

- Week X Quiz: Reflection questions about team performance in some activity (e.g. idea generation/decision making)

- Final Exam (Scenario-based questions about modeling, professionalism, and ethics)

- Final individual assessment: Course instructional assessment of individual contributions from peer evaluations

The instructional team attempted to use the functionality of the Learning Management System (LMS), D2L Brightspace. The decision to require both supervised and unsupervised assessments, and to allow multiple attempts throughout the term, prevented the use of the built-in Competency tool. Instead, logic statements in the course gradebook were used to ensure that each of the supervised and non-supervised categories were met (AND functions), and IF/MAX $(\mathrm{OR})$ statements were used to ensure students had multiple opportunities to demonstrate each competency. A mixture of hidden and visible gradebook items was used to capture grades that fed into the parent formula-based items.

\section{Communication}

Students tracked their own progress by looking at their gradebook to see their progress on the competencies. A video/graphic was created to communicate to students the framework and how they could track progress using their gradebook. The graphic also informed on when each competency was going to be assessed and in what format.

Intelligent agents in the LMS were also used to automate the communication of competency status to students. The agents checked competency gradebook items at key points and informed students whether they had passed or not passed. If they had not passed, the email communicated the next opportunity to pass. Intelligent agents cannot report on formula-based gradebook items so originating individual gradebook items were used to report on them.

The number of variables were an issue in the second report cycle as the intelligent agent had to look at all possible combinations of grade level to determine who received passing or not passing messaging. To overcome this, we downloaded the grades from the formula-based grade items and uploaded to a new hidden points-based grade item and used those to run the intelligent agents. For the third round of communication most students had passed all competencies, and students still requiring different competencies were easily identifiable, meaning that we could export directly to a spreadsheet and use a mail merge for the final communication.

Teamwork was reported on separately as it required different messaging due to this competency not being finalized until the end of the course.

\section{Tasks/Adjustments while Course was Running}

As this was a pilot, the implementation of CBA was modified as issues were identified. These issues included:

- It is common practice to deduct marks from deliverables when submitted late to discourage procrastination and teach elements of professionalism. However, this does not align with providing scores aligned completely with demonstrated performance. For this pilot there were often two different sets of grades for some deliverables, which could be replaced with a standalone grade for timely submission.

- Certain online quiz questions were linked to competencies, requiring extraction of individual question marks for populating competency gradebook items. In the future this would be improved by using separate quizzes for competency assessment that directly feed competency gradebook items.

- A significant number of students did not meet expectations during the midterm supervised assessment of modeling and communication skills. In order to avoid having the final exam be the only future opportunity, a makeup assessment was provided for those who did not meet expectations.

- Modifications to final rubrics required rebuilding the competency reporting logic during the course. This task could be eliminated if the major deliverables were finalized before building the competency structure.

The inability to use the built-in competency structure required students to consult specific gradebook items that were manually updated. Since the gradebook already had a 
significant number of assessments, the process to review competencies was somewhat confusing for students.

Strictly applying the stated CBA scheme would have resulted in a failure rate of approximately $10 \%$. The intent was to identify and address weaknesses where possible, rather than significantly delay progression in the program, so the course requirement of demonstrating all competencies in supervised and unsupervised activities was modified during course delivery. It was complex to provide opportunities for students repeat non-supervised assessments as they were individual sections of team reports and required significant effort to regrade. As a result, the course team decided to not require students to meet the non-supervised competency. Also, the reflection competency was reduced to $50 \%$ of the final measure in order to not fail students for this competency.

With these changes, the remaining students who did not meet the requirements were required to do an additional make-up task in follow-up activities the next semester. Students with specific weaknesses were monitored and supported to address those weaknesses.

\section{CONCLUSIONS AND RECOMMENDATIONS}

The instructional team concluded that the implementation of CBA in the course allowed learning outcomes data to be used much more rapidly than in the past to identify and improve student performance. For example, identifying that a number of students fell below expectations on a midterm assessment led the team to create an additional assessment that allowed 35 students to improve and meet the expectation. Most importantly, the approach highlighted to students how they were performing, allowing them to focus on weaknesses, and allowing the instructional team to provide additional assistance as needed.

After completing the pilot and adapting the grading scheme, the vast majority of the students who did not meet all competencies also failed the course based on the weighted mean of their assessments, so the final pass rate was comparable to previous years. However, the number who passed through the course without meeting core learning outcomes was far less; past learning outcomes data suggest that at least 50 students would fall below expectations in at least one key learning outcome while still passing the course. The adapted CBA approach identified here reduced that number to zero, though the competency requirements were adjusted during the course to acknowledge that this was a pilot. This pilot highlights the number of students who can slip through in large

CEEA-ACEG21; Paper 117

University of Prince Edward Island; June 21 - 23, 2021- 4 of 5 - integrative courses without meeting all fundamental goals unless competencies are tracked.

Following on this pilot, some suggestions are provided for implementing a version of CBA beyond what is provided in literature reviews (e.g., [4]):

- Review past grade and learning outcome data, where possible, to identify the most significant weaknesses and likely consequences of applying CBA to course assessment.

- Consider running CBA in parallel with a traditional grading scheme to avoid making significant changes in failure rate that are not in the students' favour.

- Plan to monitor performance and adapt the requirements

- The complexity of applying CBA to authentic activities, in this case team design reports, is much higher than for individual tests. This can be costly for manual regrading.

- Additional resources for regrading and remediation can be valuable.

The course team from this paper is planning to implement CBA again in the next academic year. In order to minimize manual activities, the team plans to adjust the CBA scheme to better accommodate the technical limitations of the LMS, and provide additional opportunities for repeating authentic activities.

\section{References}

[1] M.L. Cruz, G.N. Saunders-Smits, P. Groen, Evaluation of competency methods in engineering education: a systematic review, Eur. J. Eng. Educ. 45 (2020) 729-757.

[2] J.B. Frey, R. Banow, DEVELOPMENT OF "INTRODUCTION TO ENGINEERING" COURSES FOR FIRST YEAR ENGINEERING STUDENTS: A FOCUS ON STUDENT ATTITUDES, Proc. Can. Eng. Educ. Assoc. CEEA. (2020).

[3] J.B. Frey, S. Maw, S. Bens, J. Bugg, B. Sparling, Design of a Completely New First Year Engineering Program at the University of Saskatchewan - Part II, Proc. Can. Eng. Educ. Assoc. CEEA. (2019).

[4] M. Henri, M.D. Johnson, B. Nepal, A Review of Competency-Based Learning: Tools, Assessments, and Recommendations, J. Eng. Educ. 106 (2017) 607638.

[5] C.R. Johnston, D.J. Caswell, D.M. Douglas, M.J. Eggermont, A COMPETENCY-BASED, STUDENT-CENTERED ASSESSMENT MODEL 
FOR ENGINEERING DESIGN, Proc. Can. Eng. Educ. Assoc. CEEA. (2004).

[6] S. Maw, Design of a Completely New First Year Engineering Program at the University of Saskatchewan, Proc. Can. Eng. Educ. Assoc. CEEA. (2018).
[7] T. O’Neill, N. Larson, J. Smith, M. Donia, C. Deng, W. Rosehart, R. Brennan, Introducing a scalable peer feedback system for learning teams, Assess. Eval. High. Educ. 44 (2019) 848-862.

[8] How CBME Works | School of Medicine | Queen's University, (n.d.).

[9] Competency Assessment, (n.d.). 